\title{
Portable Chest X - Ray in COVID -19 Positive Cases in a Tertiary Care Centre in Central India. (A Retrospective Analysis of 739 Cases)
}

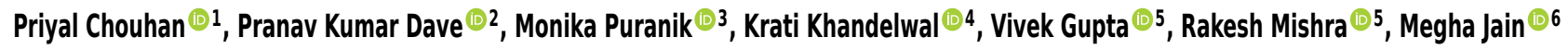 \\ ${ }^{1}$ Resident, Department of Radiodiagnosis, L N Medical College and J K Hospital, Kolar Road, Bhopal, Madhya Pradesh, India, ${ }^{2}$ Associate Professor, Department of \\ Radiology, L N Medical College and J K Hospital, Kolar Road, Bhopal, Madhya Pradesh, India, ${ }^{3}$ Assistant Professor, Department of Radiology, L N Medical College and J K \\ Hospital, Kolar Road, Bhopal, Madhya Pradesh, India, ${ }^{4}$ Senior Resident, Department of Radiology, L N Medical College and J K Hospital, Kolar Road, Bhopal, Madhya \\ Pradesh, India, ${ }^{5}$ Professor, Department of Radiology, L N Medical College and J K Hospital, Kolar Road, Bhopal, Madhya Pradesh, India, ${ }^{6}$ Professor \& HOD, Department \\ of Radiology, L N Medical College and J K Hospital, Kolar Road, Bhopal, Madhya Pradesh, India.
}

\section{Abstract}

Background: Coronavirus disease 2019 (COVID-19) (SARS-CoV-2) is an ongoing global health emergency. The virus came to first notice, as a cause of pneumonia of unknown etiology in Wuhan, Hubei Province, China at the end of 2019. In February 2020, the International Committee on Taxonomy of Viruses (ICTV) named it Severe Acute Respiratory Coronavirus -2 (SARS COV-2). Now, COVID-19 has spread all over the world and has been declared a pandemic disease. Diagnosis of COVID -19 is made on clinical history and confirmation is done by RT -PCR. Portable chest radiography is the first imaging modality that can be used to detect lung abnormalities and get follow up when required. Radiological findings observed in various CXR are ground-glass opacity/haziness, Consolidations, Peripheral air space opacities, diffuse air space involvement, and uncommon findings - pleural effusion, cavitation, pneumothorax, subcutaneous emphysema and pneumomediastinum. Use of Portable CXR is helpful to avoid transport of patients to CT room and subsequently avoid frequent decontamination of the CT room. Portable CXR is of much value where CT facility is not available and its use reduces radiation dose to patients and radiation staff. The objective is to analyze chest X-ray findings in proven cases of COVID -19 as per classification of British Society of Thoracic Imaging (BSTI) in the form of various radiological patterns and severity assessment. Subjects and Methods: This is a retrospective study of chest X-ray of COVID-19 positive patients, confirmed by RT-PCR and was admitted to designate COVID center: LNMC and JK Hospital, Bhopal in the duration of 31 July 2020 to 31 Aug 2020. Chest X-ray of 739 patients was studied and the mean age group was calculated. Lung involvement and pattern of distribution of disease were analyzed and classified according to BSTI classification and documented in frequencies and percentages. Results: In our retrospective analysis of a total of $739 \mathrm{CXR}$ of which the number of males was $457(61.84 \%)$ and the number of females was $282(38.16 \%)$. The average age group was ranging from 0 (1month) year age to 90 years age with the mean age group of 41 to 50 (20.2\%). The mean age of the patients was 40.5 years. 393 (53.1\%) patients have normal chest radiographs. Conclusion:The radiological findings in patients with COVID-19 infection varies with the severity of the disease. In the early phase of the disease, CXR was normal. The most common findings are basal / lower lobe consolidation more on right, followed by ground glass densities, peripheral air space densities, diffuse airspace disease. Basal / lower lobe consolidation was the usual findings in the mild category. In the moderate category, a variable pattern of all findings was seen. In the severe category of disease, diffuse air space densities and peripheral air space opacities were seen. Pleural effusion is the least seen.

Keywords: Portable CXR, COVID-19, Severe acute respiratory syndrome coronavirus 2, SARS-CoV-2, Pneumonia, Chest Findings in coronavirus disease, British Society of Thoracic Imaging BSTI.

Corresponding Author: Pranav Kumar Dave, Associate Professor, Department of Radiology, L N Medical College and J K Hospital, Kolar Road, Bhopal, Madhya Pradesh, India.

E-mail: pranavkdave@rediffmail.com

Received: 15 October 2020

Revised: 01 December 2020

Accepted: 09 December 2020

Published: 30 December 2020

\section{Introduction}

The pandemic spread of Coronavirus disease 2019, (COVID -19) started from Wuhan, China after December 2019. [1] The first case was reported in our country in January 2020. The SARS - CoV-2 spectrums vary from asymp- tomatic/mild respiratory symptoms to severe acute respiratory syndrome. ${ }^{[2,3]}$ Diagnosis of SARS COV-2 is confirmed on reverse transcription-polymerase chain reaction (RT-PCR) according to WHO. ${ }^{[4]}$ Several early radiological studies reported the importance of the role of imaging in the detection and management of COVID-19/SARS. ${ }^{[5,6]}$ Portable 
CXRs are the first and most commonly performed imaging on COVID-19 cases. ${ }^{[7]}$ Based on European patients, the British Society of Thoracic Imaging (BSTI) has classified CXRs findings in mild, moderate and severe form. The clinical presentations, CXR, and arterial blood gas analysis in RT-PCR positive patients are recommended because of their wide and easy availability to support initial clinical diagnosis and management of COVID -19 patients. ${ }^{[8,9]}$ The studies on CXR findings in COVID-19 are limited. ${ }^{[10-12]}$ The use of lung ultrasound is still unclear. ${ }^{[13]}$ CT scan of the lung in COVID -19 cases is preferred investigation for diagnosis and also in follow up but is not feasible as screening due to its non availability in peripheral areas, more time consuming, with comparative high radiation and necessity of decontamination. ${ }^{[14]}$

The purpose of the current study was to analyze various abnormal findings in chest X-rays, classify these based on the British Society of Thoracic Imaging classification and evaluate any deviation from the previous study.

\section{Subjects and Methods}

This is a retrospective study of chest $\mathrm{x}$-ray of patients confirmed of COVID-19 infection by RT- PCR on nasopharyngeal swab samples according to international guidelines (4). The study included all symptomatic and asymptomatic cases that came in contact with COVID-19 positive cases and tested positive on RT-PCR.

\section{Inclusion Criteria}

1. All patients with positive RT PCR status

\section{Exclusion Criteria}

1. All cases with negative RT PCR Status

2. Follow up CXR of COVID - 19 patients

Sample size: All cases admitted in our COVID center.

Place: Designated COVID center: LNMC and JK Hospital, Bhopal.

Duration of study: 31 July 2020 to 31 Aug 2020.

The machine used: Portable X-ray unit $100 \mathrm{~mA}$ with DR and CR system. All cases underwent Chest $\mathrm{x}$-ray by portable machine at the time of admission.

A posterior-anterior (PA) view of CXR in full inspiration was preferred. Otherwise, an anterior-posterior (AP) view was taken at the bedside. PACS stored Images were reviewed by radiologists and classified as per BASI classification. The findings considered in the evaluation of CXR were presence or absence, and the pattern of distribution of pulmonary alterations. Various radiological findings were evaluated

\begin{tabular}{lll}
\hline \multicolumn{2}{l|}{ Table 1: Sex wise distribution } & \\
\hline Total & Male & Female \\
739 & $457(62 \%)$ & $282(38 \%)$ \\
\hline
\end{tabular}

according to Fleischner Society's nomenclature available in Glossary of Term for Thoracic Imaging: ${ }^{[15]}$

- Ground glass densities were defined as an area of hazy, increased opacification of lung parenchyma not obscuring blood vessels and bronchi.

- Consolidation is defined as homogenous opacification of lung parenchyma obscuring blood vessels and bronchi.

- The reticular alteration, as a collection of innumerable small linear opacities that, by summation produce an appearance of a net.

The distribution of these alterations was classified as uni or bilateral with the involvement of the upper, middle, and lower lung fields. The horizontal distribution of the lesions was evaluated based on the involvement of the peripheral or central location or both. Lesions within $2 \mathrm{cms}$ from lobar bronchial structures are considered Central lesions. Peripheral lesions are defined as lesions in the remaining lung area between the central zone and the pleura.

Uncommon CXR findings in COVID-19 patients are pleural effusion, lung cavitation, pneumothorax, subcutaneous emphysema and pneumomediastinum. ${ }^{[7]}$

\section{Results}

A total of $739 \mathrm{CXR}$ were evaluated during the specified period July 31, 2020, to 31 August 2020 of which 457 (61.8\%) were male and $282(38.1 \%)$ were female [Table 1]. ${ }^{[16]}$ Male predilection was noted in the study. The age range was from 1 month ( 0 years) to 90 years old. The average age was 40.5 years. 3 patients were less than 1 year of age. [Table 2] 


\begin{tabular}{|ll|}
\hline \multicolumn{2}{|c|}{ Table 2: Age-wise distribution } \\
\hline Age group & Total \\
\hline $00-10$ & $31(4.19 \%)$ \\
\hline $11-20$ & $56(7.57 \%)$ \\
\hline $21-30$ & $152(20.56 \%)$ \\
$31-40$ & $133(17.99 \%)$ \\
\hline $41-50$ & $150(20.29 \%)$ \\
\hline $51-60$ & $127(17.18 \%)$ \\
\hline $61-70$ & $63(8.52 \%)$ \\
\hline $71-80$ & $18(2.43 \%)$ \\
\hline $81-90$ & $8(1.08 \%)$ \\
\hline 90 & $1(0.13 \%)$ \\
\hline
\end{tabular}


CXR findings were classified according to BSTI COVID 19 Classifications. Various alternations in lung pattern were quantified as normal, non-covid findings, mild, moderate and severe category. The majority of CXR were normal in $393(53.1 \%)$, and $258(34.9 \%)$ were falling in the mild category. Rest of $55(7.4 \%)$ and $21(2.8 \%)$ had moderate and severe involvement respectively [Table 3,4]. Also, a greater percentage of the older population showed severe involvement of lung.
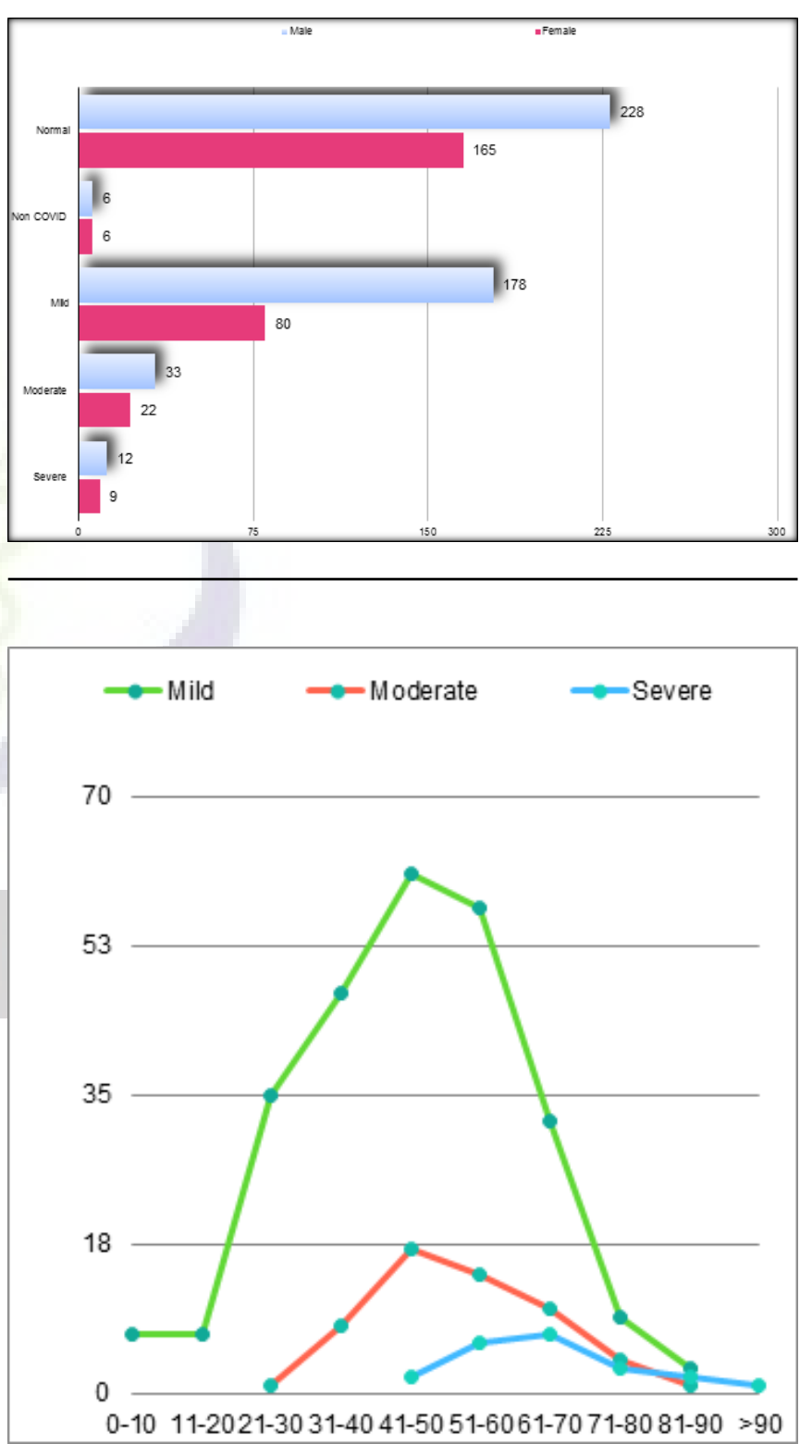

Diffuse lung involvement was noted in 24/739 (3.2\%) and peripheral lung involvement was noted in $46 / 739$ (6.2\%) of patients. Most of the patients had bilateral lower/basal lung consolidation in 130/739 (17.6\%) of patients and right lower lobe consolidation in 123/739 (16.6\%) of patients. GGO was seen in $19(2.5 \%)$ patients only.[Table 5] 


\begin{tabular}{|c|c|c|c|}
\hline Category/grading & Male & Female & Total \\
\hline Normal & 228 & 165 & $393(53.17 \%)$ \\
\hline Non-COVID & 6 & 6 & $12(1.62 \%)$ \\
\hline Mild & 178 & 80 & $258(34.91 \%)$ \\
\hline Moderate & 33 & 22 & $55(7.44 \%)$ \\
\hline \multirow[t]{2}{*}{ Severe } & 12 & 9 & $21(2.84 \%)$ \\
\hline & 457 & 282 & 739 \\
\hline
\end{tabular}

Table 4: CXR Category with age-wise distribution

\begin{tabular}{llll}
\hline & Mild & Moderate & Severe \\
$0-10$ & 7 & - & - \\
$11-20$ & 7 & - & - \\
$21-30$ & 35 & 1 & - \\
$31-40$ & 47 & 8 & - \\
$41-50$ & 61 & 17 & 2 \\
$51-60$ & 57 & 14 & 6 \\
$61-70$ & 32 & 10 & 7 \\
$71-80$ & 9 & 4 & 3 \\
$81-90$ & 3 & 1 & 2 \\
$>90$ & - & - & 1 \\
\hline
\end{tabular}

Table 5: CXR pattern

\begin{tabular}{|c|c|c|c|c|c|c|c|c|c|c|c|c|}
\hline Age group & $0-10$ & $11-20$ & 21-30 & $31-40$ & $41-50$ & $51-60$ & $61-70$ & $71-80$ & $81-90$ & $>90$ & Total & $\begin{array}{l}\text { Out of } \\
739\end{array}$ \\
\hline GGO density & - & - & - & 2 & 5 & 8 & 4 & - & - & - & 19 & $2.57 \%$ \\
\hline \multirow{3}{*}{ Consoli Rt } & 7 & 4 & 23 & 28 & 22 & 25 & 10 & 3 & 1 & & 123 & $16.64 \%$ \\
\hline & - & 1 & 2 & 3 & 7 & 4 & 2 & 1 & & & 20 & $2.70 \%$ \\
\hline & - & - & 10 & 21 & 36 & 32 & 19 & 8 & 4 & & 130 & $17.59 \%$ \\
\hline $\begin{array}{l}\text { Peripheral air } \\
\text { space opacities }\end{array}$ & - & 1 & 2 & 4 & 14 & 8 & 10 & 6 & - & 1 & 46 & $6.22 \%$ \\
\hline $\begin{array}{l}\text { Diffuse air } \\
\text { space }\end{array}$ & - & - & - & 2 & 3 & 9 & 8 & 2 & - & - & 24 & $3.24 \%$ \\
\hline Other findings & 1 & 1 & 1 & 3 & 12 & 5 & 6 & 4 & 2 & 1 & 36 & $4.87 \%$ \\
\hline
\end{tabular}

\section{Discussion}

COVID-19 disease is an ongoing pandemic across the world. Diagnosis is confirmed on RT-PCR. The commonest presentation of disease varies from asymptomatic, to mild respiratory symptoms or severe acute respiratory syndrome. A portable CXR is a baseline radiological investigation for evaluation of the severity of disease due to easy availability, cost-effectiveness, minimal radiation exposure and lower risk of infection for the other patients including radiographer. The policy of radiation safety measures as per "as low as reasonably achievable" (ALARA) is followed.

A chest $x$-ray is an insensitive tool reaching up to $69 \%$. Also it has low sensitivity in differentiating other viral pneumonia, pulmonary edema etc. ${ }^{[11,15,17,18]}$ The American College of Radiologists (ACR) and the Fleischner Society have suggested that imaging is not advised for patients who tested positive by RT-PCR who were asymptomatic or have mild symptoms, and CT scan should be reserved for patients with a progressive disease course. ${ }^{[19,20]}$ Also, due to the high infective rate and cumbersome decontamination of CT suite, ACR has also suggested that portable CXR may be considered for disease 
evaluation. ${ }^{[21]}$

In our study, every COVID-19 positive patient admitted to our hospital had an initial portable CXR. Sergio Giuseppe Vancheri et al reported 25\% normal CXR in RT-PCR positive cases. 393 (53.17\%) of patients showed normal CXR in our study, probably because of tracking and tracing and testing of patients who came in contact with COVID-19 positive patients, therefore, preventing further spread of disease. Mild involvement is seen in $258(34.9 \%)$ patients, moderate in 55 $(7.4 \%)$ and severe in $21(2.8 \%)$.

The mean age is 40.5 years and males were more affected. Most of the affected population range is $41-50$ years. The patient age group of 41-50 years is most commonly infected in our region, with mild to moderate lung involvement. Severe lung involvement is seen in higher age of $>60$ years. Indicating that a patient's age is also a risk factor for severe involvement of the disease.

Wong et al reviewed $255 \mathrm{CXR}$ in 64 patients, describing the time course of the radiographic findings of COVID-19 pneumonia with 31\% negative baseline examination. The commonest CXR findings were GGO and reticular pattern alone or in combination with other alterations, as described in other studies. ${ }^{[22-24]}$ Sparing of upper lung fields is similar to the distribution pattern seen in H1N1 influenza pneumonia. ${ }^{\text {[25] }}$ Our results showed that bilateral lower lobe consolidation is the most common finding detected on CXR than GGO and reticular opacities, as CXR is less sensitive for GGOs.

Our study showed predominantly bilateral lower lobe distribution and unilateral involvement were more common on the right side. Also, the peripheral involvement of the lung was more common than the central part of the lung. ${ }^{[1]}$ Similar results were noted in Wong et al demonstrating bilateral lung involvement in the majority of cases. ${ }^{[10]}$ Predominant lower lobe involvement was reported in several other studies. ${ }^{26,27]}$ Only two COVID-19 patients showed pleural effusion which is an uncommon finding. ${ }^{[28]}$

The limitation of our study includes a lack of correlation with the clinical complaint of patients and interval change of CXR. Besides, the onset of symptoms was not uniform at the time of admission. And there is a lack of CXR findings with CT chest findings correlation.

\section{Representative Images}
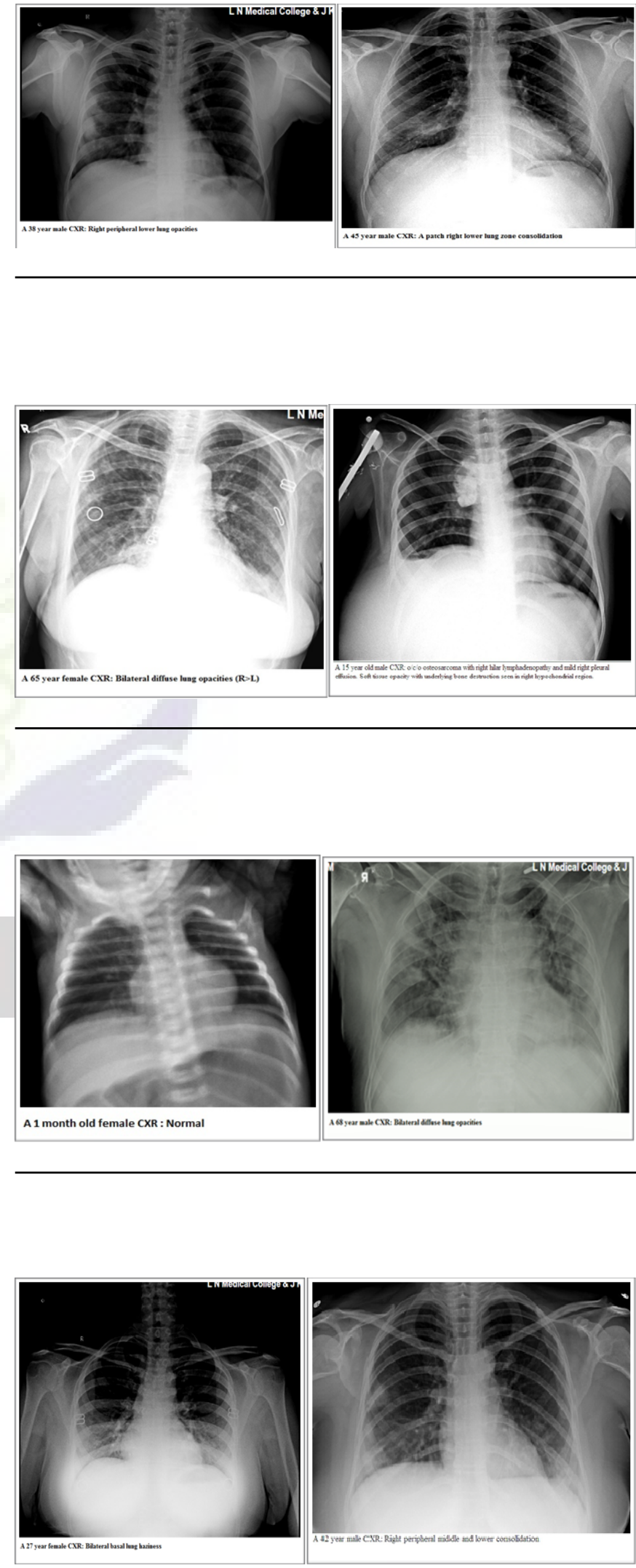

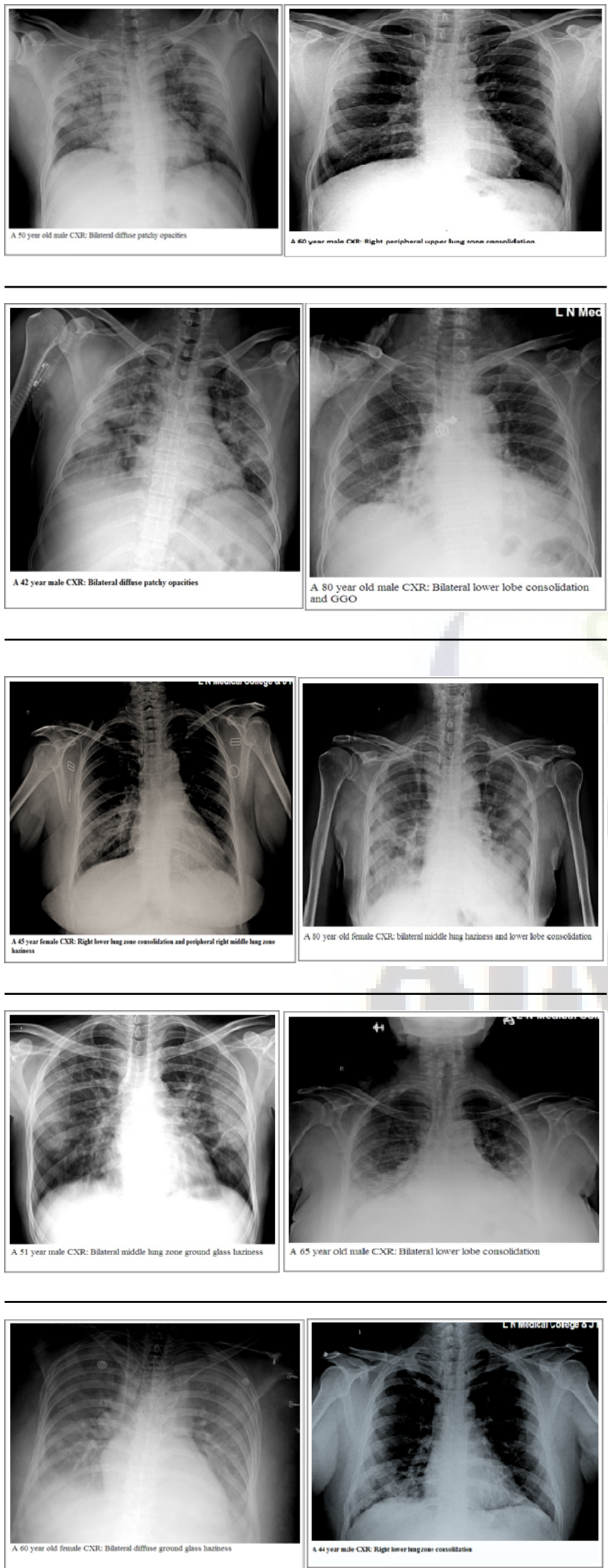
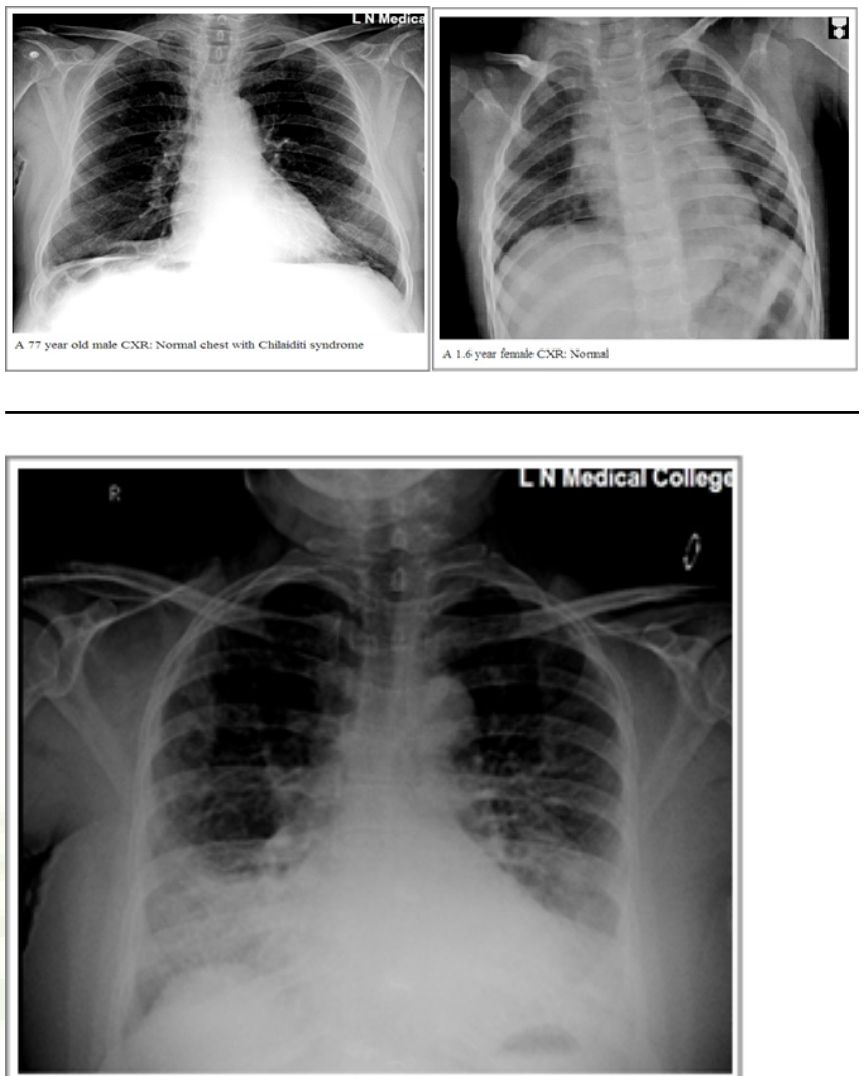

A 48 year feamle CXR: Bilateral mäddle and lower lobe consolidation

\section{Conclusion}

CXR in COVID -19 cases is a baseline initial imaging investigation as there is an increasing number of cases, A portable CXR is easily available at the bedside with less use of radiation and reduced infection risk issues used in case of CT. Portable CXR findings were used to filter the cases for $\mathrm{CT}$. Various patterns of lung involvement can be identified on CXR like ground-glass opacities, $\mathrm{Bi}$ or unilateral lower lobe consolidation, peripheral air space, diffuse air space alteration. The commonest findings were lower zone involvement on the Right side. Pleural effusion was seen in only two cases. During the early phase of the disease, CXR may be normal, Current observations are consistent with previously studied to use portable CXR as the initial baseline imaging modality.

\section{References}

1. Vancheri SG, Savietto G, Ballati F, Maggi A, Canino C, Bortolotto C, et al. Radiographic findings in 240 patients with COVID-19 pneumonia: time-dependence after the onset of symptoms. Eur Radiol. 2020;30(11):6161-6169. Available from: https://dx.doi.org/10.1007/s00330-020-06967-7. 
2. Huang $\mathrm{C}$, Wang $\mathrm{Y}, \mathrm{Li}$ X. Clinical features of patients infected with 2019 novel coronavirus in Wuhan. Lancet. 2020;395:497506. Available from: https://doi.org/10.1016/S0140-6736(20) 30183-5.

3. Shi H, Han X, Jiang N. Radiological findings from 81 patients with COVID-19 pneumonia in Wuhan, China: a descriptive study. Lancet Infect Dis. 2020;20:425-434. Available from: https://doi.org/10.1016/S1473-3099(20)30086-4.

4. ;.

5. $\mathrm{Ng}$ MY, Lee EYP, Yang J, Yang F, Li X, Wang $\mathrm{H}$, et al. Imaging Profile of the COVID-19 Infection: Radiologic Findings and Literature Review. Radiology. 2020;2(1):200034. Available from: https://dx.doi.org/10.1148/ryct.2020200034.

6. Song F, Shi N, Shan F, Zhang Z, Shen J, Lu H. Emerging 2019 novel coronavirus (2019-nCoV) pneumonia. Radiology. 2020;295:210-217. Available from: https://doi.org/10.1148/ radiol.2020200274.

7. Jacobi A, Chung M, Bernheim A, Eber C. Portable chest Xray in coronavirus disease-19 (COVID-19): A pictorial review. Clin Imaging. 2020;64:35-42. Available from: https://dx.doi. org/10.1016/j.clinimag.2020.04.001.

8. Rubin GD, Ryerson CJ, Haramati LB, Sverzellati N, Kanne JP, Raoof S. The Role of Chest Imaging in Patient Management During the COVID-19 Pandemic: A Multinational Consensus Statement From the Fleischner Society. Chest. 2020;158(1):106-116. Available from: https://doi.org/10. 1016/j.chest.2020.04.003.

$9 . \quad$; 2020. Available from: https://www.sirm.org/wp-content/ uploads/2020/03/DI.Accessed.

10. Wong H, Lam H, Fong AH, Leung ST, Chin TWY, Lo CSY. Frequency and Distribution of Chest Radiographic Findings in Patients Positive for COVID-19. Radiology. 2019;296(2):72-78. Available from: https://doi.org/10.1148/ radiol.2020201160.

11. Yoon SH, Lee KH, Kim JY, Ko H, Kim KH, Park CM, et al. Chest radiographic and CT findings of the 2019 novel coronavirus disease (COVID-19): analysis of nine patients treated in Korea. Korean J Radiol. 2020;21(4):494-500. Available from: https://doi.org/10.3348/kjr.2020.0132.

12. Salehi S, Abedi A, Balakrishnan S, Gholamrezanezhad A. Coronavirus Disease 2019 (COVID-19): A Systematic Review of Imaging Findings in 919 Patients. Am J Roentgenol. 2020;215(1):87-93. Available from: https://dx.doi.org/10. 2214/ajr.20.23034.

13. Soldati G, Smargiassi A, Inchingolo R, Buonsenso D, Perrone $\mathrm{T}$, Briganti DF. Is there a role for lung ultrasound during the COVID-19 pandemic? J Ultrasound Med. 2020;39(7):14591462. Available from: https://doi.org/10.1002/jum.15284.

14. Durrani M, Haq IU, Kalsoom U, Yousaf A. Chest X-rays findings in COVID 19 patients at a University Teaching Hospital - A descriptive study. Pak J Med Sci. 2020;36(COVID19S4):22-26. Available from: https://dx.doi.org/10.12669/pjms. 36.covid19-s4.2778.

15. Hansell DM, Bankier AA, MacMahon H, McLoud TC, Müller NL, Remy J. Fleischner Society: Glossary of Terms for Thoracic Imaging. Radiology. 2008;246(3):697-722. Available from: https://dx.doi.org/10.1148/radiol.2462070712.

16. Joanne C, James P. Jones Melvyn M. The role of chest radiography in confirming covid-19 pneumonia. BMJ. 2020;370:2426-2426. Available from: https://doi.org/10.1136/ bmj.m2426.

17. Fang Y, Zhang H, Xie J. Sensitivity of chest CT for COVID19: comparison to RT-PCR. Radiology. 2020;296(2):115-117. Available from: https://doi.org/10.1148/radiol.2020200432.

18. Lei Y, Zhang HW, Yu J, Patlas MN. COVID-19 Infection: Early Lessons. Can Assoc Radiol J. 2020;71(3):251252. Available from: https://dx.doi.org/10.1177/ 0846537120914428 .

19. CT) for susptected COVID-19 infection/ Amercian College of Radiology. www.acr.org/advocacy-and-Economic s/ACR-Position-Statements/ Recommendations-for-ChestRadiography-and-CT-for-Suspected-COVID-19- infection. ACR recommendations for the use of chest radiography and computed tomography. 2020;27.

20. Rubin GD, Ryerson CJ, Haramati LB, Sverzellati N, Kanne JP, Raoof S. The Role of Chest Imaging in Patient Management During the COVID-19 Pandemic: A Multinational Consensus Statement From the Fleischner Society. Chest. 2020;158(1):106-116. Available from: https://doi.org/10. 1016/j.chest.2020.04.003.

21. Rousan LA, Elobeid E, Karrar M, Khader Y. Chest X-ray findings and temporal lung changes in patients with COVID-19 pneumonia. BMC Med. 2020;20(1):245-245. Available from: https://dx.doi.org/10.1186/s12890-020-01286-5.

22. Müller NL, Ooi GC, Khong PL, Nicolaou S. Severe Acute Respiratory Syndrome: Radiographic and CT Findings. Am J Roentgenol. 2003;181(1):3-8. Available from: https://dx.doi. org/10.2214/ajr.181.1.1810003.

23. Franquet T. Imaging of Pulmonary Viral Pneumonia. Radiology. 2011;260(1):18-39. Available from: https://dx.doi. org/10.1148/radiol.11092149.

24. Koo HJ, Lim S, Choe J, Choi SH, Sung H, Do KH. Radiographic and CT features of viral pneumonia. Radiographics. 2018;38:719-739. Available from: https://doi.org/10.1148/rg. 2018170048.

25. Aviram G, Bar-Shai A, Sosna J, Rogowski O, Rosen G, Weinstein I, et al. H1N1 Influenza: Initial Chest Radiographic Findings in Helping Predict Patient Outcome. Radiology. 2010;255(1):252-259. Available from: https://dx.doi.org/10. 1148/radiol.10092240.

26. $\mathrm{Zu} \mathrm{ZY,} \mathrm{Jiang} \mathrm{MD,} \mathrm{Xu} \mathrm{PP,} \mathrm{Chen} \mathrm{W,} \mathrm{Ni} \mathrm{QQ,} \mathrm{Lu} \mathrm{GM.}$ Coronavirus Disease 2019 (COVID-19): A Perspective from China. Radiology. 2020;296(2):15-25. Available from: https: //doi.org/10.1148/radiol.2020200490.

27. Bernheim A, Mei X, Huang M, Yang Y, Fayad ZA, Zhang N. Chest CT Findings in Coronavirus Disease-19 (COVID19): Relationship to Duration of Infection. Radiology. 2020;295(3):685-691.

28. Sohail S. Rational and practical use of imaging in COVID19 pneumonia. Pak J Med Sci. 2020;36. Available from: https://doi.org/10.12669/pjms.36.covid19-s4.2760. 
Copyright: (C) the author(s), 2020. It is an open-access article distributed under the terms of the Creative Commons Attribution License (CC BY 4.0), which permits authors to retain ownership of the copyright for their content, and allow anyone to download, reuse, reprint, modify, distribute and/or copy the content as long as the original authors and source are cited.

How to cite this article: Chouhan $P$, Dave PK, Puranik M, Khandelwal K, Gupta V, Mishra R, Jain M. Portable Chest X Ray in COVID -19 Positive Cases in a Tertiary Care Centre in Central India. (A Retrospective Analysis of 739 Cases). Asian J. Med. Radiol. Res. 2020;8(2):65-72.

DOI: dx.doi.org/10.47009/ajmrr.2020.8.2.11

Source of Support: Nil, Conflict of Interest: None declared. 